\title{
Virtual prototyping study shows increased ATPase activity of Hsp90 to be the key determinant of cancer phenotype
}

\author{
Shireen Vali · Rani Pallavi · Shweta Kapoor • \\ Utpal Tatu
}

Received: 17 July 2009/Revised: 22 September 2009/Accepted: 6 October 2009/Published online: 24 October 2009

(C) The Author(s) 2009. This article is published with open access at Springerlink.com

\begin{abstract}
Hsp90 is an ATP-dependent molecular chaperone that regulates key signaling proteins and thereby impacts cell growth and development. Chaperone cycle of Hsp90 is regulated by ATP binding and hydrolysis through its intrinsic ATPase activities, which is in turn modulated by interaction with its co-chaperones. Hsp90 ATPase activity varies in different organisms and is known to be increased in tumor cells. In this study we have quantitatively analyzed the impact of increasing Hsp90 ATPase activity on the activities of its clients through a virtual prototyping technology, which comprises a dynamic model of Hsp90 interaction with clients involved in proliferation pathways. Our studies highlight the importance of increased ATPase activity of Hsp90 in cancer cells as the key modulator for increased proliferation and survival. A tenfold increase in ATPase activity of Hsp90 often seen in cancer cells increases the levels of active client proteins such as Akt-1, Raf-1 and Cyclin D1 amongst others to
\end{abstract}

Shireen Vali and Rani Pallavi have contributed equally to the article.

Electronic supplementary material The online version of this article (doi:10.1007/s11693-009-9046-3) contains supplementary material, which is available to authorized users.

S. Vali $\cdot$ S. Kapoor

Cellworks Group Inc., 13962 Pierce Road, Saratoga, CA 95070, USA

S. Vali $\cdot$ S. Kapoor

Cellworks Research India Pvt. Ltd, \#303 Block A, 3rd Floor, 60 Feet Road, AECS Layout, Marathahalli Post, Bangalore,

Karnataka 560037, India

R. Pallavi · U. Tatu $(\bowtie)$

Department of Biochemistry, Indian Institute of Science,

Bangalore, Karnataka 560012, India

e-mail: tatu@biochem.iisc.ernet.in about 12-, 8- and 186-folds respectively. Additionally we studied the effect of a competitive inhibitor of Hsp90 activity on the reduction in the client protein levels. Virtual prototyping experiments corroborate with findings that the drug has almost 10- to 100-fold higher affinity as indicated by a lower $\mathrm{IC}_{50}$ value $(30-100 \mathrm{nM})$ in tumor cells with higher ATPase activity. The results also indicate a 15- to 25 -fold higher efficacy of the inhibitor in reducing client levels in tumor cells. This analysis provides mechanistic insights into the links between increased Hsp90 ATPase activity, tumor phenotype and the hypersensitivity of tumor Hsp90 to inhibition by ATP analogs.

Keywords Anti-cancer drugs · Heat shock protein . Quantitative analysis · Virtual prototyping · Hsp90 ATPase activity

\section{Introduction}

Hsp90 (Heat shock protein 90) is one of the most abundant protein of eukaryotic cells, comprising $1-2 \%$ of the total protein under non-stress conditions (Pratt and Toft 2003). It is mainly an ATP-dependent molecular chaperone which performs house-keeping functions controlling the activity, turnover, and trafficking of a variety of proteins (Pratt and Toft 2003). It plays an important role in the folding of at least 100 specific proteins of various signaling pathways that have crucial role in growth control, cell survival and development processes and in the refolding of denatured proteins during proteotoxic stress including heat, oxidative stress and acidosis (Whitesell and Lindquist 2005). A unique ATP-binding site, the Bergerat fold, exists in the $\mathrm{N}$-terminal domain of $\mathrm{Hsp} 90$ which is the characteristic of only some bacterial gyrases, topoisomerases and 
histidine-kinases besides Hsp90. This unique N-terminal ATP-binding pocket allowed for the development of specific Hsp90 inhibitors (Marcu et al. 2000; Garnier et al. 2002; Sõti et al. 2002).

The chaperone function of Hsp90 requires the formation of a multi-chaperone complex, consisting of Hsp70, Hop, p23, and Hsp40 and is dependent on ATP-binding and hydrolysis (Fig. 1; Pratt and Toft 2003; McLaughlin et al. 2002; Siligardi et al. 2004; Panaretou et al. 1998). This complex binds to key signaling proteins in the metabolic states and regulates their activities in response to appropriate stimuli. It is the inherent ATPase activity of Hsp90 which drives a conformational cycle involving transient association and dissociation of the N-terminal nucleotidebinding domains within the Hsp90 dimer (Siligardi et al. 2004). This suggests that binding of ATP to Hsp90 plays an essential role in the functioning of the Hsp90 chaperone machinery.

Human Hsp90 in its isolated form has a very weak ATPase activity (McLaughlin et al. 2002; Richter et al. 2001). The interaction of Hsp90 with its co-chaperones results in an increase in the inherent ATPase activity for Hsp90. In fact, the co-chaperones Cdc37, Aha-1, Hop and p23 modulate Hsp90 ATPase activity significantly (Siligardi et al. 2004; Kamal et al. 2004; Siligardi et al. 2002). An increased ATPase activity correlates with an increase in the Hsp90 chaperone cycle and increased processing, folding and release of the active client proteins (Pratt and Toft 2003).

Hsp90 plays a key role in the conformational maturation of many signaling proteins and protein kinases like Akt-1 (protein kinase B), Raf-1, Cdk4 (cyclin-dependent kinase 4 ), which are important regulators of cell proliferation and survival (Whitesell and Lindquist 2005; Kamal et al. 2004). All these protein kinases form novel complexes with Hsp90 and are stabilized and activated by the Hsp90 ATPdependent chaperone cycle (Sato et al. 2000; Lawlor and Alessi 2004; Schulte et al. 1995).

In this study, through a dynamic and mathematical in silico model of Hsp90 interaction with its client proteins such as Akt and Raf-1 that are involved in cell survival, proliferation and apoptosis signaling pathways, we quantitatively analyze the effects of modulation of Hsp90 ATPase activity on cell survival and proliferation endpoints (Fig. 2). Through this virtual 'what-if' analysis, we get an insight into the quantitative outcome of increasing ATPase activity of Hsp90 by different folds and the consequential fold variations in the activities of its various client proteins. Additionally, we have performed virtual experiments with an inhibitor of Hsp90. We analyzed the efficacy of the inhibitor with increasing ATPase activity and also efficacy of a range of $\mathrm{IC}_{50}$ 's of the inhibitor and its impact on the system with varying Hsp90 activity. Predictive studies through such virtual prototyping experiments are insightful in obtaining

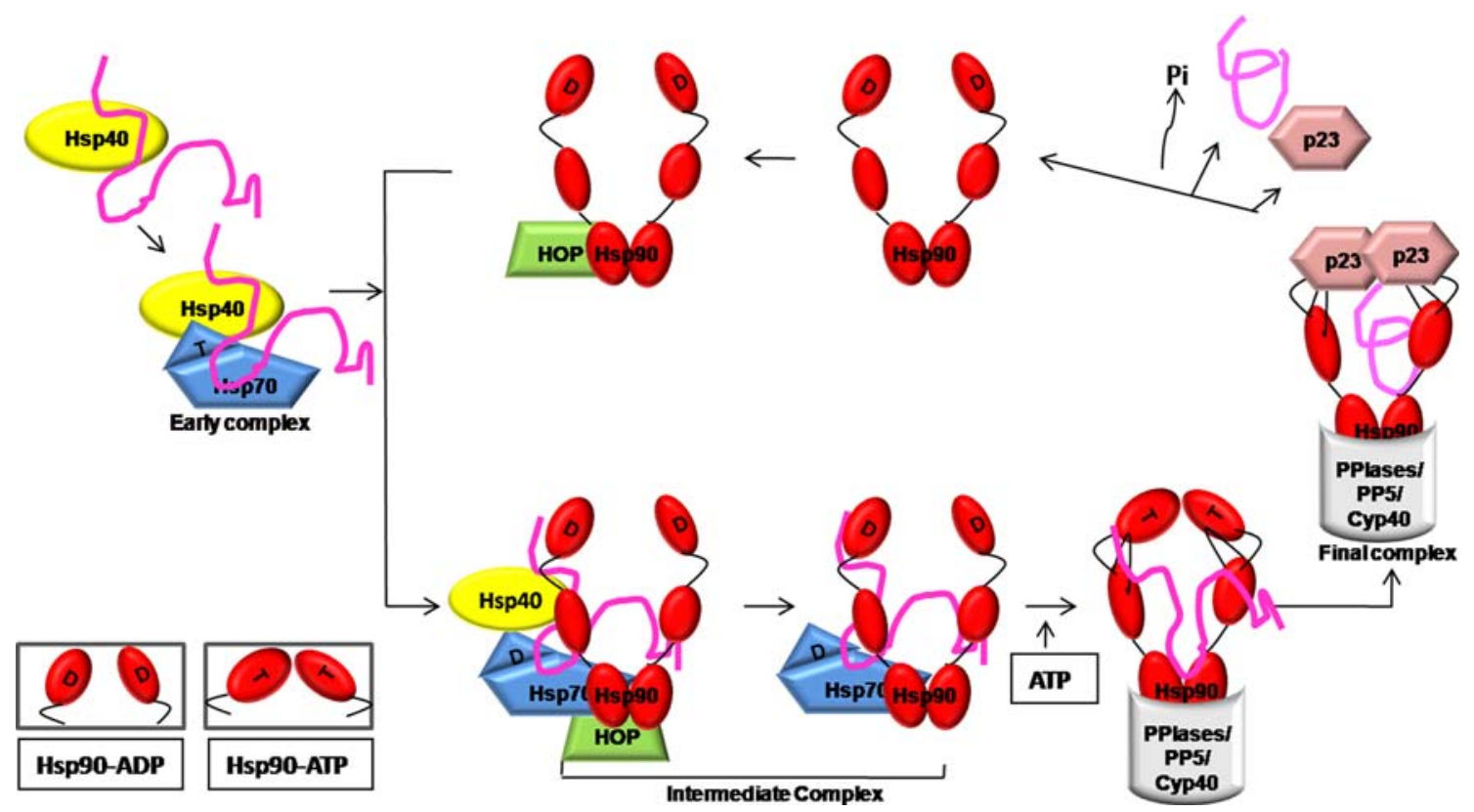

Fig. 1 ATP dependent chaperone cycle of Hsp90. The model describes the chaperone cycle of Hsp90 which depends on ATP binding and ATP hydrolysis. Partially folded protein is delivered to Hsp90-ADP via HOP which brings components of Hsp70 and Hsp90 machinery together to form intermediate complex. Hsp70 and HOP get released from this intermediate complex and ATP substitutes ADP in Hsp90. Binding of ATP to Hsp90 leads to conformational changes in N-terminal and middle domains which is required for ATP hydrolysis and substrate release. After substrate release, Hsp90 is available for the next round of chaperone cycle (adapted from Pratt and Toft 2003) 


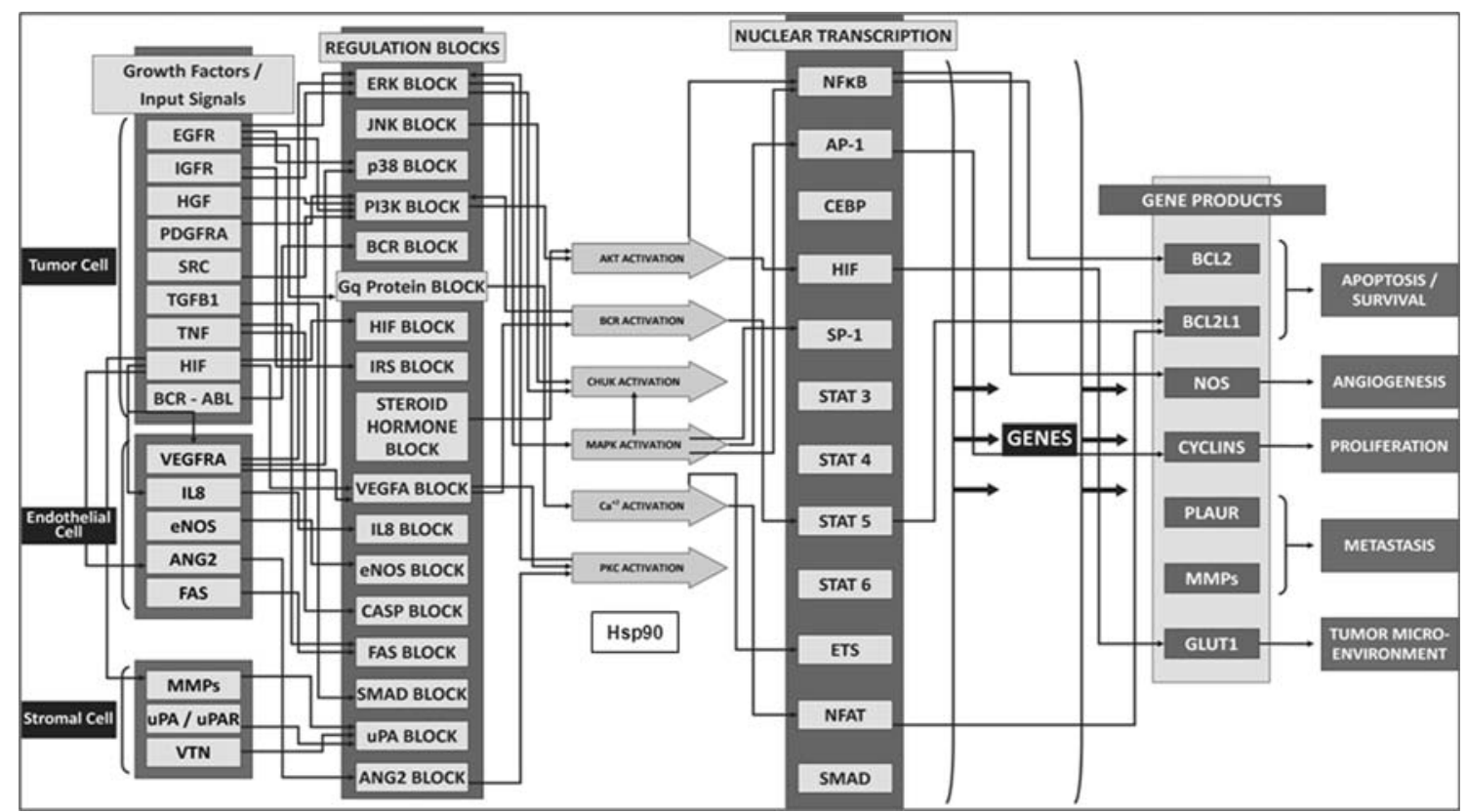

Fig. 2 Cellular processes modulated by Hsp90. The figure illustrates a high-level view for the cross-talk between the growth factor receptor pathways and major signaling cascades in tumor cells. It highlights the presence of both autocrine and paracrine signaling within the tumor cell, as well as, paracrine inputs from the endothelial and stromal cell. The growth factor receptors like epidermal growth factor receptor (EGFR), insulin-growth factor receptor (IGFR) and hepatocyte growth factor (HGF) activate signaling cascades, resulting in the activation of key kinases like Akt, IKKa, MAPKS, all of which converge at the activation of various transcription factors like NFkB, ETS1 and STATs. As a consequence of these events, downstream genes like BCL2, Cylcins and MMPs are activated which are associated with specific cancer phenotypes of proliferation, apoptosis, angiogenesis and metastasis. The cross-talk between all of the above with the basic signaling represents our control oncology platform. Hsp90 is involved in the stabilization and activation of many of these client proteins and the increase in ATPase activity has been represented as a trigger to induce the disease stage mechanistic understanding for known experimental observations such as increased Hsp90 ATPase activity in tumor cells (Kamal et al. 2003); getting semi-quantitative information on biomarker profiles; and also streamlining inhibitor kinetics.

\section{Methods}

\section{Model description}

The platform consists of the Hsp90 interactome associated with cell proliferation, survival and apoptosis processes. The reactions related to binding of Hsp90 with its client proteins and the stabilization and activation of these clients in the above cellular processes are detailed. This includes the ATP-dependent chaperoning cycle of Hsp90 and its ubiquitous role in the regulation of cellular processes. Figure 2 is the actual snapshot of the virtual system in which are highlighted different cellular processes regulated by Hsp90 that are included in this study. It is a dynamic model with each reaction represented through an ordinary differential equation and it predicts the quantitative effects on the levels of each of the Hsp90 clients, with an increase in binding affinity for ATP and Hsp90 ATPase activity. The key sections of the model are qualitatively described in Supplementary information S1, with the equations and mechanisms for each node tabulated in Supplementary information $\mathrm{S} 2$.

\section{Model construction}

The model is a dynamic representation of Hsp90 ATPdependent chaperone cycle and includes kinetic details for the regulation of Hsp90 client proteins. The time dependent client protein binding to Hsp90 multi-chaperone complex and release of the active client following ATP-hydrolysis has been done utilizing modified ordinary differential equations (ODE) and mass action kinetics. The ODEs are solved by Radau method (Raichur et al. 2006). The Cellworks proprietary technology, iC-PHYS ${ }^{\mathrm{TM}}$ has been used to create and simulate the platform.

\section{Model assumptions}

The model is a generic Hsp90 centric system and not specific to a cell type. The binding affinity of all protein kinases to Hsp90_cdc37 complex has been assumed to be 
the same. The ATP concentration is maintained at $5,000 \mu \mathrm{M}$ and ADP at 2,000 $\mu \mathrm{M}$ in the model to maintain a physiological ratio. The phosphate source has not been explicitly modeled in the system. It has been assumed that Hsp90 has a very weak ATPase activity in normal cells, with a $\mathrm{Kf}=1.5 \mathrm{E}^{-1} \mathrm{~s}^{-1}$ (McLaughlin et al. 2002; Richter et al. 2001). It has been assumed that ATP-hydrolysis results in release of active client proteins from Hsp90 chaperone complex. ATP-binding displaces cdc37 from Hsp90-chaperone complex and only then p23 binds to Hsp90 in the ATP form. The protein degradation process is mediated by ubiquitination, but in the system, all degradation processes are shown as irreversible and spontaneous reactions. A constant source for EGFL6, EGFR, IGF-1R, PDGFR, PDGF, Her2, Her3 has been assumed in the system to account for their constitutive expression due to gain of function mutations during cancer (Fredrick et al. 2000; O'Rourke et al. 1997; Puputti et al. 2006; Joensuu et al. 2005).

\section{Simulation protocol}

\section{Initial conditions}

At initial conditions the model represents normal ATPase activity for Hsp90 with a Kf of $1.5 \mathrm{E}^{-1} \mathrm{~s}^{-1}$ (optimized from the original value of $1.5 \mathrm{E}^{-3} \mathrm{~s}^{-1}$ mentioned (McLaughlin et al. 2002; Kamal et al. 2003). The client proteins remain bound to the Hsp90 chaperone complex and ATP hydrolysis drives the release of the active client proteins. Hsp90 and its co-chaperone cdc37 were maintained at a concentration of $10 \mu \mathrm{M}$ (Carrello et al. 2004) in the system.

\section{Variation in ATPase activity}

'What-if' analysis or hypothesis testing has been done to see the effects of increased ATPase activity on the cell proliferation, survival and apoptosis processes. The ATPase activity of Hsp90 has been hypothetically increased by 10-, 30- and 50-folds. Increased ATP-binding and ATPase activity of Hsp90 has been shown to occur in tumor cells (Kamal et al. 2003). The levels of the client proteins namely Akt-1, Raf-1, Casp9, Bad and Cyclin D1 have been analyzed with the variation in the ATPase activity.

\section{Inhibitor of Hsp90 ATPase activity}

A generic competitive inhibitor has been tested on the system to observe the effects of reduced Hsp90 ATPase activity on the processes of cell proliferation, survival and apoptosis. The kinetics used were for Hsp90 inhibitor 17-AAG (17-(Allylamino)-17-demethoxygeldanamycin) with a $\mathrm{Ki}$ of $4.9 \mathrm{E}^{-2} \mu \mathrm{M}$ (Kamal et al. 2003). The drug concentrations used for the study were in the range of 0.1 , $0.5,1,5$ and $10 \mu \mathrm{M}$ of the drug. It is explicitly assumed that the concentration of the drug is present at the site of action post ADME (absorption, distribution, metabolism, and excretion). Efficacy of the inhibitor with varying Hsp90 ATPase activity has been tested. Additionally, to test the sensitivity of binding of the inhibitor to systems with varying Hsp90 ATPase activity, we have tested a wide range of $\mathrm{IC}_{50}$ values in the range of $30-3,000 \mathrm{nM}$.

\section{Definitions of different states}

Control state is defined as one in which the ATPase activity is basal at $0.15 \mathrm{~s}^{-1}$. A disease state is where the ATPase activity is 50 -fold higher at $7.5 \mathrm{~s}^{-1}$. The drug was tested in the disease state at the $\mathrm{Ki}$ and concentration mentioned in "Inhibitor of Hsp90 ATPase activity"

\section{Results}

Effect on activated Akt-1 levels with increase in Hsp90 ATPase activity

Phospho Akt-1, (pAkt-1) a significant marker for cell survival, is a known interactor and a substrate for Hsp90. Cancer cells that have increased Hsp90 ATPase activity have been shown to exhibit increased active Akt-1 levels (Lawlor and Alessi 2004; Kamal et al. 2003).This observation has been analyzed using a virtual Hsp90 platform where the ATPase activity of Hsp90 has been increased by 10-, 30- and 50-folds and its effect on the active Akt-1 levels were observed (Supplementary Information S1, Sect. 1.2.1). Active Akt-1 initially shows a stoichiometric increase in levels with an increasing ATPase activity upto tenfolds, but beyond a 30-fold rise in ATPase activity the fold increase in the pAkt-1 levels increases significantly (for a 50-fold increase in the Hsp90 ATPase activity, pAkt1 increases by 120 -folds; Fig. 3a). This is due to the existing feed-forward loop from IRS1 present in the system (Supplimentay Information, Sect. 1.2.2 B). When the feedforward loop is switched off, the increase in pAkt-1 levels remains stoichiometric even with a 50-folds increase in Hsp90 ATPase activity (Fig. 3b). A comparison between the two effects has been done in Fig. 3c. As a result of increased Akt-1 activation with increase in Hsp90 activity, the downstream targets of Akt-1 in the survival, proliferation and apoptosis signaling pathways are also increased. An example of the downstream effects of Akt-1 is the inactivation due to increased phosphorylation of proapoptotic proteins such as Caspase 9 and BAD, as shown in Fig. 3d. This shows that with an increase in Hsp90 ATPase 
(a)
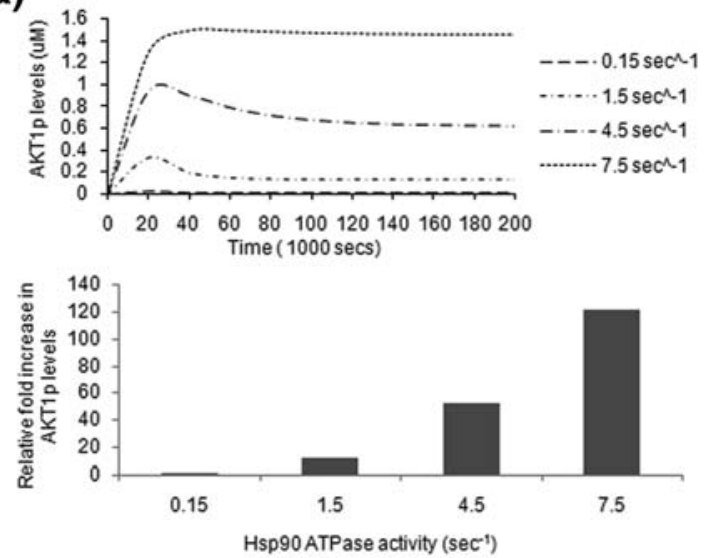

(c)

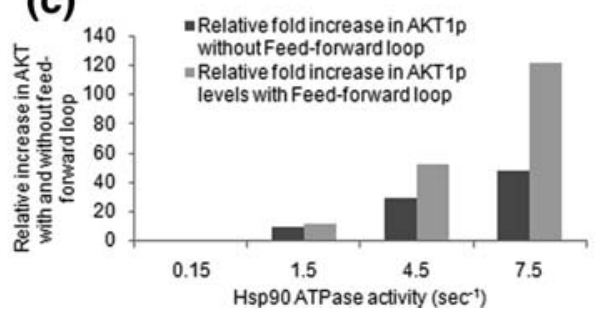

Fig. 3 Effect of increasing Hsp90 ATPase activity on Akt-1 and its downstream targets. a Shows increase in active Akt-1 level with feedforward loop. b Shows increase in active Akt-1 level without feedforward loop. The upper panel in $\mathbf{a}$ and $\mathbf{b}$ show the graphic representation of simulation. Simulation program was run for $2 \times 10^{5} \mathrm{~s}$ and the protein concentration was taken when it reaches

activity there is a simultaneous increase in the antiapoptotic effect.

The effect of increasing ATPase activity on Raf-1P levels

Raf-1P is another major Hsp90 client and an important player in the cell proliferation pathway. Raf- 1 is stabilized and activated by Hsp90. Activated Raf-1, further activates many downstream transcription factors like ELK-1, ATF-2, NFkB, B-catenin and AP-1, resulting in the expression of Cyclin D1. Cyclin D1 forms an active complex with the cell-cycle kinase Cdk4 and helps in the G1-S phase transition (Kamal et al. 2004; Goetz et al. 2003), acting as a key biomarker for cell proliferation. With a 50-folds increase in the Hsp90 ATPase activity, Raf-1P level was found to be increased by 35 -fold. However, a dramatic increase in the levels of Cyclin D1 (180-folds) is seen even with a tenfold increase in the ATPase activity, thereby indicating an increase in cell proliferation. This dramatic increase in Cyclin D1 levels can be attributed to an increase in all the transcription factors responsible for its synthesis. All the above transcription factors are known to transcribe Cyclin D1 and a reasonable increase in each of (b)
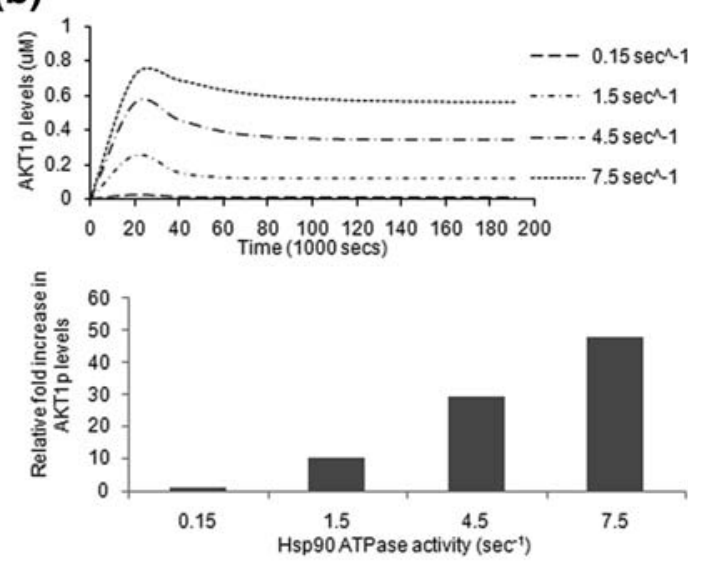

(d)

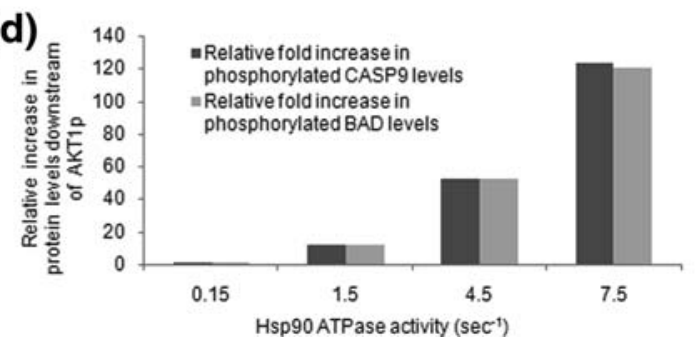

saturation. c Comparison between relative change in Akt-1 level with and without feed-forward loop. d Activated levels of downstream targets of Akt-1 in the survival pathway also increases with increasing Hsp90 ATPase activity. The increase in CASP9p and BADp levels corroborates with that of Akt-1

these levels occurs with the increasing Hsp90 ATPase activity. Figure 4 highlights the effect of increasing ATPase activity on Raf-1P and Cyclin D1 levels, respectively obtained through virtual prototyping studies.

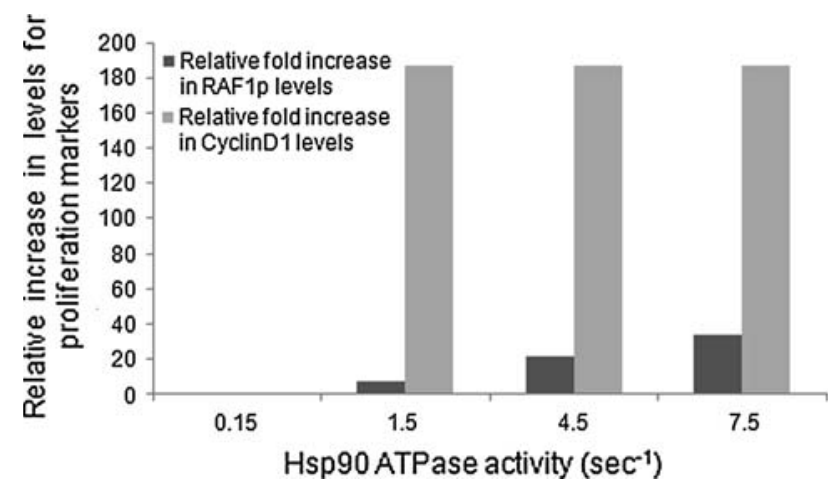

Fig. 4 Effect of increasing Hsp90 ATPase activity on Raf-1P and Cyclin D1 levels. Raf-1, a major Hsp90 client protein, is an oncogene and when over-activated, results in tumor cell proliferation by the AP1 mediated expression of Cyclin D1. An increase in Hsp90 ATPase activity results in an increased level of Raf-1P and Cyclin D1 
Analysis of the effects of a competitive inhibition of Hsp90 ATPase activity on cell survival and proliferation endpoints

As indicated by the trends seen an increase in the ATPase activity of Hsp90 results in an increase in the levels of active Hsp90 client proteins that are key players in cell proliferation and survival. We have analyzed how an inhibitor of Hsp90 ATPase activity would affect these endpoints (Methods in "Inhibitor of Hsp90 ATPase Activity"). The inhibitor was represented to competitively inhibit the ATP binding to Hsp90 and thereby interfere with the normal ATPase cycle of Hsp90 (Goetz et al. 2003; Banerji et al. 2005; Richter et al. 2001).

Virtual experimental studies reveal that Akt-1 which increases by 120 -folds when ATPase activity is 50 -fold higher than baseline (representative of a cancer condition), is reduced by almost 24-folds with $1 \mu \mathrm{M}$ concentration of the generic inhibitor. Similarly, Raf-1P shows an 18-fold reduction in levels after having increased to 35 -folds in the high ATPase condition (Fig. 5).

Inhibiting Hsp90 ATPase activity does seem to have a significant impact on the key tumor survival and proliferation markers such as pAkt-1 and Raf-1P, as supported by successful outcomes of clinical trials of Hsp90 inhibitors such as 17-AAG, 17-DMAG, IPI-504, SNX-7081, Novobiocin (Banerji et al. 2005; Abramson et al. 2008; Sydor et al. 2006; Rice et al. 2008). Hsp90 has been widely accepted as a potential cancer therapeutic target (Goetz et al. 2003; Radanyi et al. 2008; Messaoudi et al. 2008).

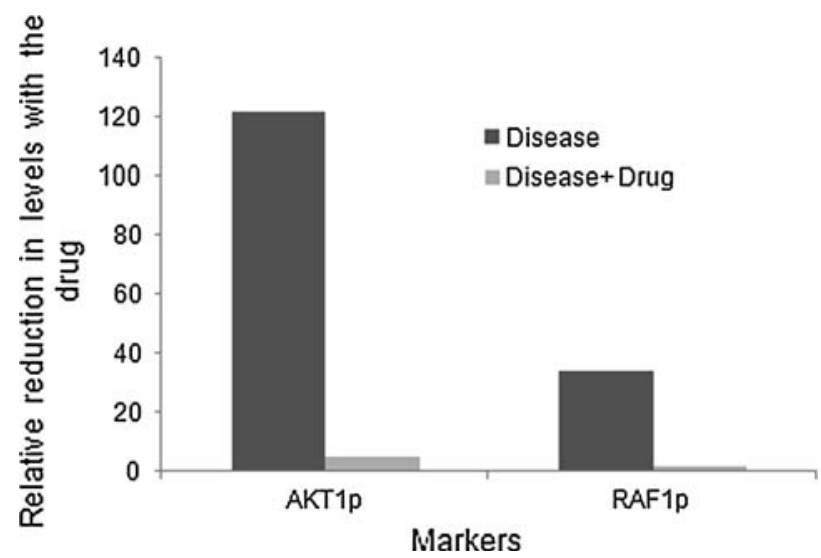

Fig. 5 Effect of Hsp90 ATPase inhibitor in diseased state on Akt1 and Cyclin D1 levels. The above graph shows the fold decrease in the active Akt-1 and Raf-1P levels in presence $1 \mu \mathrm{M}$ of the inhibitor during disease
Differential sensitivity of the inhibitor with varying Hsp90 ATPase activity

We analyzed the inhibitor binding affinity and efficacy of reducing the cell survival endpoints through monitoring reduction in activated Akt-1 levels. It was observed that with $1 \mu \mathrm{M}$ concentration of the inhibitor with $\mathrm{Ki}$ of $4.9 \mathrm{E}^{-2}$, active Akt-1 levels were reduced by almost 24 -folds when the ATPase activity was $7.5 \mathrm{~s}^{-1}$ (50-fold) as compared to only 12-folds with an ATPase activity of $1.5 \mathrm{~s}^{-1}$ (30-fold; Fig. 6a). This data clearly indicates that the inhibitor would be more efficacious when ATPase activity for Hsp90 is higher, as is seen in cancer cells (Kamal et al. 2003) as compared to cells with a lower ATPase activity (normal cells). Virtual prototyping studies reveal that the inhibitor will be more effective or sensitive in a cancer condition marked by a sequential increase in the ATPase activity for Hsp90 (Fig. 6a).

We also analyzed the drug efficacy by increasing $\mathrm{IC}_{50}$ values for the inhibitor (range between 30 and 3,000 nM) at a constant drug concentration of $1 \mu \mathrm{M}$. A higher $\mathrm{IC}_{50}$ value would essentially mean a lower binding affinity for the drug and vice versa. It was seen that tumor cells generally have a lower $\mathrm{IC}_{50}$ value (Kamal et al. 2003). As shown in Fig. 6b, the drug effectiveness in reducing pAkt-1 levels at $1 \mu \mathrm{M}$ concentration is decreasing with an increase in $\mathrm{IC}_{50}$ values. The drug is effective upto an $\mathrm{IC}_{50}$ of
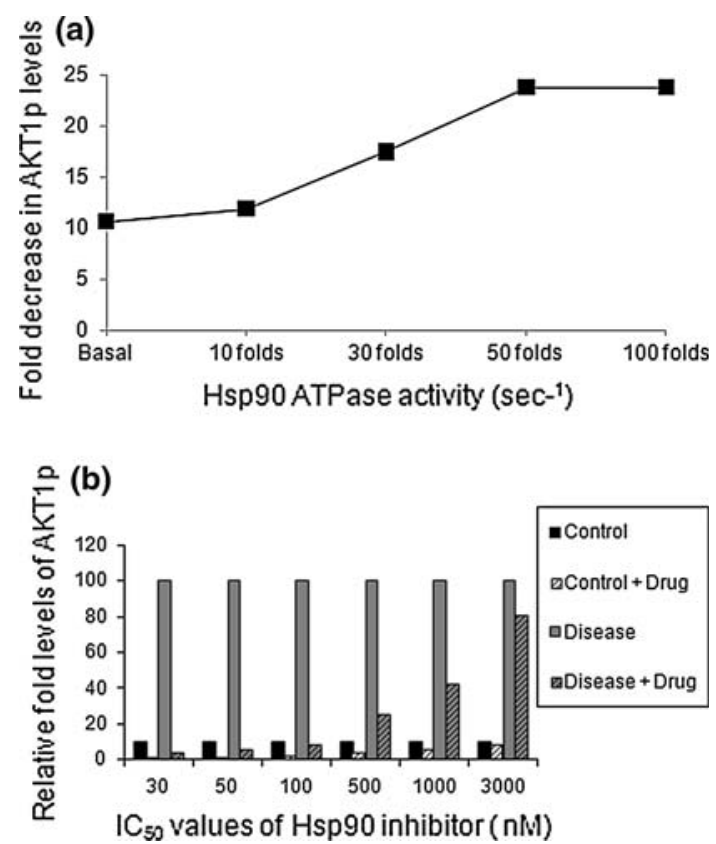

Fig. 6 Drug efficacy with increase in Hsp90 ATPase activity. a The above graph shows that the fold decrease in the active Akt-1 levels, because of the inhibitor, increases with the increasing ATPase activity for Hsp90. b Differential efficacy of drug on control versus diseased state with variation in drug $\mathrm{IC}_{50}$. The fold decrease in the active Akt1 levels decreases with increasing $\mathrm{IC}_{50}$ of the drug 
$100 \mathrm{nM}$ beyond which negligible reduction of pAkt-1 is seen. It shows the highest reduction of pAkt-1 by 35 -folds at an $\mathrm{IC}_{50}$ of $30 \mathrm{nM}$. The impact of this inhibition on a normal cell with high $\mathrm{IC}_{50}$ value (in the range of $\mu \mathrm{M}$ ) will be less as compared to tumor cell with low $\mathrm{IC}_{50}$ value (in the range of $\mathrm{nM}$ ). This analysis indicates that not only the inhibition of Hsp90 ATPase activity is more effective in conditions where the system has higher ATPase activity such as a tumor cell but also it would have higher binding affinity to this state over a normal state. This study suggests that inhibition of Hsp90 ATPase activity with a drug having a low $\mathrm{IC}_{50}$ value less than $100 \mathrm{nM}$ would be beneficial in impacting the key tumor endpoints of proliferation and survival without much perturbation to the normal system.

\section{Discussion}

Hsp90 is an ATP-dependent molecular chaperone which performs house-keeping functions controlling the activity, turnover, and trafficking of a variety of proteins (Pratt and Toft 2003). It serves as a key convergent node in the cell signaling circuit not just for the human cell types but for other organisms as well, based on the concept of common circuitry and design across varied life forms. The Hsp90 molecular machinery is dependent on ATPbinding and hydrolysis and operates as a multi-chaperone complex. Recent evidence suggests an intricate link between Hsp90 ATPase activity and structural dynamics accompanying its chaperoning cycle and the universality of this across different organisms (Southworth and Agard 2008).

There has been experimental evidence of different states of a system (i.e., normal vs. tumor states) having varying Hsp90 ATPase activity (Kamal et al. 2003). Furthermore, the Hsp90 activity characterized from different organisms exhibit widely different ATPase activities (Owen et al. 2002). While the reason underlying varying ATPase activities of Hsp90 from different systems remain unknown, this study makes an effort to quantitatively study the consequence of this variation in its catalytic efficiency on maturation of its client proteins and its overall impact on organism growth. Virtual analysis shown here has also revealed that variation in catalytic activities of Hsp90 from different systems may confer differential sensitivities to small molecule inhibitors of Hsp90. This dynamic, computational, quantitative analysis of Hsp90 networks shown here provides a theoretical framework to analyze the impact of varying its ATPase activity on maturation of its clients, progression through signaling pathways and organism growth. In addition, it provides a basis to predict the extent of growth inhibition conferred by generic Hsp90 inhibitors on organisms with differing Hsp90 ATPase acitivities.

Hsp90 is a molecular target for cancer therapeutics and Hsp90 inhibitors are now widely being tested in clinical trials for depletion of clients including several oncogenic kinases (Kamal et al. 2004; Goetz et al. 2003; Issacs et al. 2002; Stepanova et al. 1996; Smith et al. 2008). More than being just a cancer therapeutic target, Hsp90 inhibitors are now extensively being tested for treatment of other diseases including neurodegenerative disorders (Waza et al. 2005; Dickey et al. 2007), rheumatoid arthritis (Rice et al. 2008), diabetes (Yang et al. 2009), malaria as well as other infectious diseases of fungal and viral origin (Banumathy et al. 2003; Wider et al. 2009; Nicola et al. 2008; Chase et al. 2008). The regulation of various client proteins by Hsp90 highlights its ubiquitous role in various organisms like Plasmodium falciparum (Banumathy et al. 2003; Acharya et al. 2007), Candida albicans (Solit and Chiosis, 2008), Aspergillus fumigates, Cryptococcus neoformans (Cardenas et al. 1999) and Vaccinia virus (Hu and Seeger 1996).

In light of the key role of Hsp90 in many organisms and disease processes, we analyzed the effect of a generic Hsp90 competitive inhibitor on the system and could substantially conclude from the results that the sensitivity (binding affinity) towards inhibition would increase with the increasing ATPase activity for Hsp90. For instance, a tenfold increase in ATPase activity has shown $12 \%$ increase (Fig. 6a) in inhibition by an Hsp90 inhibitor like geldanamycin. The analysis has also shown that inhibition of ATPase activity of Hsp90 is efficacious in reducing the cell survival and proliferation endpoints.

The results support the notion that an increased ATPase activity for Hsp90 during cancer (Kamal et al. 2003) would also increase its sensitivity to a particular inhibitor targeting inhibition of its ATPase activity. Hence, a specific Hsp90 inhibitor would be more effective against a cancer cell with higher ATPase activity in preference to a normal cell. Our studies indicate that an inhibitor to Hsp90 such as 17-AAG, 17-dimethylaminoethylamino-17-demethoxy-geldanamycin (17-DMAG) would be 15- to 25-fold more effective against a cancer cell with a higher ATPase activity as compared to the normal cell with a very weak ATPase activity for Hsp90. Reducing survival and proliferation specifically of the tumor cells is the need of an hour in order to overcome the toxic side effects of chemotherapeutic drugs.

Hsp90 inhibitors presently under clinical trials include 17-AAG (NC1, Kosan Biosciences), KOS-953 (Kosan Biosciences), CNF-1010 and CNF-2024 (Biogen Idec), IPI-504 (Infinity Pharmaceuticals) and SNX-5422 (Serenex; Solit and Chiosis 2008). Most of these are now under Phase II and Phase III clinical trials. These inhibitors induce depletion of the clients by blocking the binding of ATP to 
Hsp90 and hence inhibiting the ATPase chaperone cycle. Other inhibitors that target co-chaperone proteins like Cdc37 (Smith et al. 2008) and Hop (Yi and Regan 2008) are also being studied as an alternative approach to inhibit Hsp90 mediated activation of various client proteins.

This dynamic virtual system can also be used to study the role of Hsp90 activity on other phenotypes that are affected in cancer such as increased angiogenesis, metastasis, and increased expression of drug resistance proteins. Through this study we present a novel approach for target validation and understanding the efficacy of manipulating a target in normal versus abnormal cell systems. The study strongly supports the role of Hsp90 as a "Master switch" for cell survival and proliferation and a therapeutic target (Goetz et al. 2003; Banerji et al. 2005; Beliakoff and Whitesell 2004).

Acknowledgments Authors sincerely thank Dr. Fred Gorin for reviewing the manuscript and giving his valuable feedback. R. P acknowledges Junior Research Fellowship from the Council of Scientific and Industrial Research, New Delhi, India. UT acknowledges DBT, DST, New Delhi, India and Malsig for their financial support.

\section{Statement of conflicts of interest None.}

Open Access This article is distributed under the terms of the Creative Commons Attribution Noncommercial License which permits any noncommercial use, distribution, and reproduction in any medium, provided the original author(s) and source are credited.

\section{References}

Abramson JS, Chen W, Juszczynski P, Takahashi H, Neuberg D, Kutok JL, Takeyama K et al (2008) The heat shock protein 90 inhibitor IPI-504 induces apoptosis of AKT-dependent diffuse large B-cell lymphomas. Br J Haematol 144:358-366

Acharya P, Kumar R, Tatu U (2007) Chaperoning a cellular upheaval in malaria: heat shock proteins in Plasmodium falciparum. Mol Biol Parasitol 153:85-94

Banerji U, Walton M, Raynaud F, Grimshaw R, Kelland L, Valenti M et al (2005) Pharmacokinetic-pharmacodynamic relationships for the heat shock protein 90 molecular chaperone inhibitor 17-allylamino, 17-demethoxygeldanamycin in human ovarian cancer xenograft models. Clin Cancer Res 11:7023-7032

Banumathy G, Singh V, Pavithra SR, Tatu U (2003) Heat shock protein 90 function is essential for Plasmodium falciparum growth in human erythrocytes. J Biol Chem 278:18336-18345

Beliakoff J, Whitesell L (2004) Hsp90: an emerging target for breast cancer therapy. Anticancer Drugs 15:651-662

Cardenas ME, Cruz MC, Del Poeta M, Chung N, Perfect JR, Heitman J (1999) Antifungal activities of antineoplastic agents: Saccharomyces cerevisiae as a model system to study drug action. Clin Microbiol Rev 12:583-611

Carrello A, Allan RK, Morgan SL, Owen BA, Mok D, Ward BK et al (2004) Interaction of the Hsp90 cochaperone cyclophilin 40 with Hsc70. Cell Stress Chaperones 9:167-181

Chase G, Deng T, Fodor E, Leung BW, Mayer D, Schwemmle M et al (2008) Hsp90 inhibitors reduce influenza virus replication in cell culture. Virology 377:431-439
Dickey CA, Kamal A, Lundgren K, Klosak N, Bailey RM, Dunmore J et al (2007) The high-affinity HSP90-CHIP complex recognizes and selectively degrades phosphorylated tau client proteins. J Clin Invest 117:648-658

Fredrick L, Wang XY, Eley G, James CD (2000) Diversity and frequency of epidermal growth factor receptor mutations in human glioblastomas. Cancer Res 60:1383-1387

Garnier C, Lafitte D, Tsvetkov PO, Barbier P, Leclerc-Devin J, Millot JM et al (2002) Binding of ATP to heat shock protein 90: evidence for an ATP-binding site in the C-terminal domain. J Biol Chem 277:12208-12214

Goetz MP, Toft DO, Ames MM, Erlichman C (2003) The Hsp90 chaperone complex as a novel target for cancer therapy. Ann Oncol 14:1169-1176

Hu J, Seeger C (1996) Hsp90 is required for the activity of a hepatitis B virus reverse transcriptase. Proc Natl Acad Sci USA 93:1060 1064

Issacs J, Xu W, Neckers L (2002) Heat shock protein 90 as a molecular target for cancer therapeutics. Cancer Cell 3:213-217

Joensuu H, Puputti M, Sihto H, Tynninen O, Nupponen NN (2005) Amplification of genes encoding KIT, PDGFRA and VEGFR2 receptor tyrosine kinases is frequent in glioblastoma multiforme. J Pathol 207:224-231

Kamal A, Thao L, Sensintaffar J, Zhang L, Boehm MF, Fritz LC et al (2003) A high-affinity conformation of Hsp90 confers tumor selectivity on Hsp90 inhibitors. Nature 425:407-410

Kamal A, Boehm MF, Burrows FJ (2004) Therapeutic and diagnostic implications of Hsp90 activation. Trends Mol Med 10:283-290

Lawlor MA, Alessi DR (2004) PKB/AKT: a key mediator of cell proliferation, survival and insulin responses? J Cell Sci 114: 2903-2910

Marcu MG, Doyle M, Bertolotti A, Ron D, Hendershot L, Neckers L (2000) Heat shock protein 90 modulates the unfolded protein response by stabilizing IRE1. Mol Cell Biol 22:8506-8513

McLaughlin SH, Smith HW, Jackson SE (2002) Stimulation of the weak ATPase activity of human hsp90 by a client protein. J Mol Biol 315:787-798

Messaoudi S, Peyrat JF, Brion JD, Alami M (2008) Recent advances in Hsp90 inhibitors as antitumor agents. Anticancer Agent Med Chem 8:761-782

Nicola AM, Andrade RV, Dantas AS, Andrade PA, Arraes FB, Fernandes L et al (2008) The stress responsive and morphologically regulated hsp 90 gene from Paracoccidioides brasiliensis is essential to cell viability. BMC Microbiol 8:158

O'Rourke DM, Qian X, Zhang HT, Davis JG, Nute E, Meinkoth J et al (1997) Trans receptor inhibition of human glioblastoma cells by erbB familyectodomains. Proc Natl Acad Sci USA 7:3250-3255

Owen BA, Sullivan WP, Felts SJ, Toft DO (2002) Regulation of heat shock protein 90 ATPase activity by sequences in the carboxyl terminus. J Biol Chem 277:7086-7091

Panaretou B, Prodromou C, Roe SM, O'Brien R, Ladbury JE, Piper PW et al (1998) ATP binding and hydrolysis are essential to the function of the Hsp90 molecular chaperone in vivo. EMBO J $17: 4829-4836$

Pratt WB, Toft DO (2003) Regulation of signaling protein function and trafficking by the hsp90/hsp70-based chaperone machinery. Expt Biol Med 228:111-133

Puputti M, Tynninen O, Sihto H, Blom T, Mäenpää H, Isola J et al (2006) Amplification of KIT, PDGFRA, VEGFR2, and EGFR in gliomas. Mol Cancer Res 4:927-934

Radanyi C, Le Bras G, Marsaud V, Peyrat JF, Messaoudi S, Catelli MG et al (2008) Antiproliferative and apoptotic activities of tosylcyclonovobiocic acids as potent heat shock protein 90 inhibitors in human cancer cells. Cancer Lett 274:88-94 
Raichur A, Vali S, Gorin F (2006) Dynamic modeling of alphasynuclein aggregation for the sporadic and genetic forms of Parkinson's disease. Neuroscience 142:859-870

Rice JW, Veal JM, Fadden RP, Barabasz AF, Partridge JM, Barta TE et al (2008) Small molecule inhibitors of Hsp90 potently affect inflammatory disease pathways and exhibit activity in models of rheumatoid arthritis. Arthritis Rheum 58:3765-3775

Richter K, Muschler P, Hainzl O, Buchner J (2001) Coordianted ATP hydrolysis by the Hsp90 Dimer. J Biol Chem 276:3368933696

Sato S, Fujita N, Tsuruo T (2000) Modulation of AKT kinase activity by binding to Hsp90. Proc Natl Acad Sci USA 97: 10832-10837

Schulte TW, Blagosklonny MV, Ingui C, Neckers L (1995) Disruption of the Raf-1-Hsp90 molecular complex results in destabilization of raf-1 and loss of Raf-1-Ras association. J Biol Chem 270:24585-24588

Siligardi G, Panaretou B, Meyer P, Singh S, Woolfson DN, Piper PW et al (2002) Regulation of Hsp90 ATPase activity by the co-chaperone Cdc37p/p50cdc37. J Biol Chem 277:20151-20159

Siligardi G, Hu B, Panaretou B, Piper PW, Pearl LH, Prodromou C (2004) Co-chaperone regulation of conformational switching in the Hsp90 ATPase cycle. J Biol Chem 279:51989-51998

Smith JR, Clarke PA, de Billy E, Workman P (2008) Silencing the cochaperone CDC37 destabilizes kinase clients and sensitizes cancer cells to HSP90 inhibitors. Oncogene 28:157-169

Solit DB, Chiosis G (2008) Development and application of Hsp90 inhibitors. Drug Discov Today 13:38-43
Sõti C, Nagy E, Giricz Z, Vígh L, Csermely P, Ferdinandy P (2002) Heat shock proteins as emerging therapeutic targets. $\mathrm{Br} \mathrm{J}$ Pharmacol 146:769-780

Southworth DR, Agard DA (2008) Species-dependent ensembles of conserved conformational states define the Hsp90 chaperone ATPase cycle. Mol Cell 32:631-640

Stepanova L, Leng X, Parker SB, Harper JW (1996) Mammalian p50Cdc37 is a protein kinase-targeting subunit of Hsp90 that binds and stabilizes Cdk4. Genes Dev 10:1491-1502

Sydor JR, Normant E, Pien CS, Porter JR, Ge J, Grenier L et al (2006) Development of 17-allylamino-17-demethoxygeldanamycin hydroquinone hydrochloride (IPI-504), an anti-cancer agent directed against Hsp90. Proc Natl Acad Sci USA 103:1740817413

Waza M, Adachi H, Katsuno M, Minamiyama M, Sang C, Tanaka Fet al (2005) 17-AAG, an Hsp90 inhibitor, ameliorates polyglutaminemediated motor neuron degeneration. Nature 11:1088-1095

Whitesell L, Lindquist S (2005) Hsp90 and the chaperoning of cancer. Nature 5:761-772

Wider D, Péli-Gulli MP, Briand PA, Tatu U, Picard D (2009) The complementation of yeast with human or Plasmodium falciparum Hsp90 confers differential inhibitor sensitivities. Mol Biochem Parasitol 164:147-152

Yang B, Zhao D, Verkman AS (2009) Hsp90 inhibitor partially corrects nephrogenic diabetes insipidus in a conditional knock-in mouse model of aquaporin-2 mutation. FASEB J 23:503-512

Yi F, Regan L (2008) A novel class of small molecule inhibitors of Hsp90. ACS Chem Biol 3:645-654 